\title{
New Phenylpropanoid Glycosides from Juniperus communis var. depressa
}

\author{
Naoki Iida,${ }^{a, 1)}$ Yuka Inatomi,${ }^{a}$ Hiroko Murata,${ }^{a}$ Jin Murata,${ }^{b}$ Frank A. Lang, ${ }^{c}$ Toshiyuki TanaKa, ${ }^{d}$ \\ Tsutomu NAKANISHI, ${ }^{a}$ and Akira INADA ${ }^{*}, a$ \\ ${ }^{a}$ Faculty of Pharmaceutical Sciences, Setsunan University; 45-1 Nagaotoge-cho, Hirakata, Osaka 573-0101, Japan. \\ ${ }^{b}$ Botanical Gardens, Koishikawa, Graduate School of Science, The University of Tokyo; 3-7-1 Hakusan, Bunkyo-ku, Tokyo \\ 112-0001, Japan: ' Department of Biology, Southern Oregon University; 1250 Siskiyou, Ashland, OR 97520-5071, U.S.A.: \\ and ${ }^{d}$ Gifu Pharmaceutical University; 5-6-1 Mitahora-higashi, Gifu 502-8585, Japan. \\ Received December 24, 2009; accepted March 2, 2010; published online March 4, 2010
}

Two new phenylpropanoid glycosides were isolated from the leaves and stems of Juniperus communis var. depressa (Cupressaceae) along with 14 known compounds. Their structures were determined by spectral analyses, in particular by 2D-NMR spectral evidence.

Key words Juniperus communis var. depressa; Cupressaceae; phenylpropanoid glycoside; lignan glycoside

In a survey of chemical components from useful plants grown in western North America, we have reported a number of chemical compounds (nine phenylpropanoids, six neolignans, fourteen flavonoids, seven catechins, and five terpenoids) from the leaves and stems of Juniperus communis var. depressa (Cupressaceae). ${ }^{2-6)}$ In our continuing study on this plant, two new phenylpropanoid glycosides (1 and 4), were isolated together with six known phenyl propanoides (2, 3, 5-8), two known phenolic compounds (9, 10), and six known lignans $(\mathbf{1 1}-\mathbf{1 6})$. This paper describes the structural elucidation of the new compounds as well as the characterization of the absolute structures of three lignans $(\mathbf{1 1}, \mathbf{1 2}, \mathbf{1 4})$ based on NMR and circular dichroism (CD) spectral evidence.

The $n$ - $\mathrm{BuOH}$ soluble part of the $\mathrm{MeOH}$ extract was separated by a combination of silica gel, octadecyl silica gel (ODS), and Sephadex LH-20 column chromatographies, followed by HPLC separation, to afford two new compounds (1 and 4) and 14 known compounds (2, 3, 5-16). The known compounds were identified as junipediol B 8-O- $\beta$-D-glucopyranoside (2), ${ }^{7)}$ junipediol A 8 - $O$ - $\beta$-D-glucopyranoside (3), ${ }^{7}$ $(7 S, 8 S)$-guaiacylglycerol $(\mathbf{5}),{ }^{8,9)}$ junipetrioloside $\mathrm{A}(\mathbf{6}),{ }^{10)}$ trans-coniferyl aldehyde (7), ${ }^{11)}$ 2-[4-(3-hydroxypropyl)-2methoxyphenoxy]-1,3-propanediol $(8),{ }^{12)}$ vanillin $(9),{ }^{13}$ arbutin (10), ${ }^{13)}(2 S, 3 R)-2,3$-dihydro-7-hydroxy-3-hydroxymethyl-2-(4' -hydroxy-3' -methoxyphenyl)-5-benzofuranpropanol $4^{\prime}-O$ - $\beta$-D-glucopyranoside $(\mathbf{1 3}),{ }^{14)}$ (2R,3S)-2,3-dihydro-3-hydroxymethyl-7-methoxy-2-(4'-hydroxy-3' methoxyphenyl)-5-benzofuranpropanol $4^{\prime}-O-\beta$-D-glucopyranoside (15), ${ }^{15)}$ and cupressoside A (16) ${ }^{16)}$ by comparison of physical data with literature values and spectroscopic evidence. The structures of the isolates $(\mathbf{1}-\mathbf{1 6})$ are given in Chart 1.

Compound 1, a white amorphous powder, showed the $[\mathrm{M}-\mathrm{H}]^{-}$ion peak at $m / z 489.1604$ in the negative ion high resolution (HR) FAB-MS, indicating the molecular formula to be $\mathrm{C}_{21} \mathrm{H}_{30} \mathrm{O}_{13}$. The ${ }^{1} \mathrm{H}$ - and ${ }^{13} \mathrm{C}$-NMR spectral data (Table 1) showed the presence of a $\beta$-D-glucopyranosyl and an $\alpha$-Larabinofuranosyl moieties in $\mathbf{1}$. Identification of monosaccharides, including its absolute configuration, was carried out by direct HPLC analysis of the acid hydrolysate. The ${ }^{1} \mathrm{H}$ NMR and ${ }^{1} \mathrm{H}-{ }^{1} \mathrm{H}$ correlation spectroscopy (COSY) spectra of 1 showed the presence of a 1,2,4-trisubstituted benzene ring $[\delta 6.83(1 \mathrm{H}, \mathrm{s}, \mathrm{H}-2), 6.73(1 \mathrm{H}, \mathrm{d}, J=8.1 \mathrm{~Hz}, \mathrm{H}-5)$, and $6.75(1 \mathrm{H}$, br d, $J=8.1 \mathrm{~Hz}, \mathrm{H}-6)]$, aliphatic $\mathrm{CH}_{2} \mathrm{OH}-\mathrm{CH}(\mathrm{Ar})$ $\mathrm{CH}_{2} \mathrm{O}$-moiety $[\delta 3.02(1 \mathrm{H}, \mathrm{m}, \mathrm{H}-7), 4.07(1 \mathrm{H}, \mathrm{dd}, J=10.6$, $7.6 \mathrm{~Hz}, \mathrm{H}-8 \mathrm{a}), 3.77$ (1H, dd, $J=10.6,4.0 \mathrm{~Hz}, \mathrm{H}-8 \mathrm{~b}), 3.84$ $(1 \mathrm{H}, \mathrm{dd}, J=11.6,5.5 \mathrm{~Hz}, \mathrm{H}-9 \mathrm{a})$, and 3.73 (1H, overlapping signal, H-9b)], and a methylenedioxy group $[\delta 5.88(2 \mathrm{H}, \mathrm{s}$, $\left.\mathrm{H}_{2}-10\right)$ ] (Table 1). In addition, long-range correlations between $\mathrm{H}-7 / \mathrm{C}-1$ and $\mathrm{H}_{2}-10 / \mathrm{C}-3, \mathrm{C}-4$ were observed in the heteronuclear multiple bond correlation spectroscopy (HMBC) spectrum (Fig. 1). Based on this spectral evidence, the aglycone of 1 was determined to be junipediol B. ${ }^{7)}$ The position of the glycosyl moiety in $\mathbf{1}$ was decided by the following HMBC and nuclear Overhauser enhancement spectroscopy (NOESY) experiments (Fig. 1), in which the HMBC correlations $\left(\mathrm{H}-1^{\prime} / \mathrm{C}-8\right.$ and $\left.\mathrm{H}-1^{\prime \prime} / \mathrm{C}-6^{\prime}\right)$ as well as the NOESY correlations $\left(\mathrm{H}-1^{\prime} / \mathrm{H}_{2}-8\right.$ and $\left.\mathrm{H}-1^{\prime \prime} / \mathrm{H}_{2}-6^{\prime}\right)$ were observed. Therefore the $\alpha$-L-arabinofuranosyl-( $1 \rightarrow 6)-\beta$-D-glucopyranosyl moiety was connected to 8-hydroxyl group of junipediol B through a glycosidic bond. In the ${ }^{1} \mathrm{H}-$ and ${ }^{13} \mathrm{C}-\mathrm{NMR}$ spectrum, anomeric proton and anomeric carbon signals of both glucose and arabinose in $\mathbf{1}$ appeared as sets of signals, respectively. This is attributed to the presence of the diastereomers as a result of the glycosidation at 8-hydroxy group of the achiral junipediol B. ${ }^{7}$ Attempts to separate both diastereomers were unsuccessful. In conclusion, the structure of $\mathbf{1}$ was determined to be junipediol B 8-O-(6'-O- $\alpha$-L-arabinofuranosyl)- $\beta$-D-glucopyranoside.

Compound 4, a white amorphous powder, showed the $[\mathrm{M}-\mathrm{H}]^{-}$ion peak at $m / z 427.1615$ in the negative ion HRFAB-MS, corresponding to the molecular formula of $\mathrm{C}_{20} \mathrm{H}_{28} \mathrm{O}_{10}$. The ${ }^{1} \mathrm{H}$ - and ${ }^{13} \mathrm{C}-\mathrm{NMR}$ spectra of 4 closely resembled those of rosarin [=trans-cinnamyl alcohol 9- $O-\left(6^{\prime}-O-\alpha-\right.$ L-arabinofuranosyl)- $\beta$-D-glucopyranoside] isolated from the same plant. ${ }^{3)}$ However, in the ${ }^{1} \mathrm{H}-\mathrm{NMR}$ spectrum, the coupling constant between $\mathrm{H}-7$ and $\mathrm{H}-8(J=11.6 \mathrm{~Hz})$ in 4 was smaller than that of rosarin $(J=15.9 \mathrm{~Hz})$, indicating the $\mathrm{H}$ $7 / \mathrm{H}-8 \mathrm{cis}$ configuration of the aglycone. Thus the structure of 4 was concluded to be cis-cinnamyl alcohol 9- $O-\left(6^{\prime}-O-\alpha-\mathrm{L}-\right.$ arabinofuranosyl)- $\beta$-D-glucopyranoside.

Compound 11, a white amorphous powder, gave the $[\mathrm{M}-\mathrm{H}]^{-}$ion peak at $\mathrm{m} / \mathrm{z} 545.1667$ in the negative ion HRFAB-MS, indicating the molecular formula to be $\mathrm{C}_{27} \mathrm{H}_{30} \mathrm{O}_{12}$. In addition, the negative ion FAB-MS gave a fragment peak 


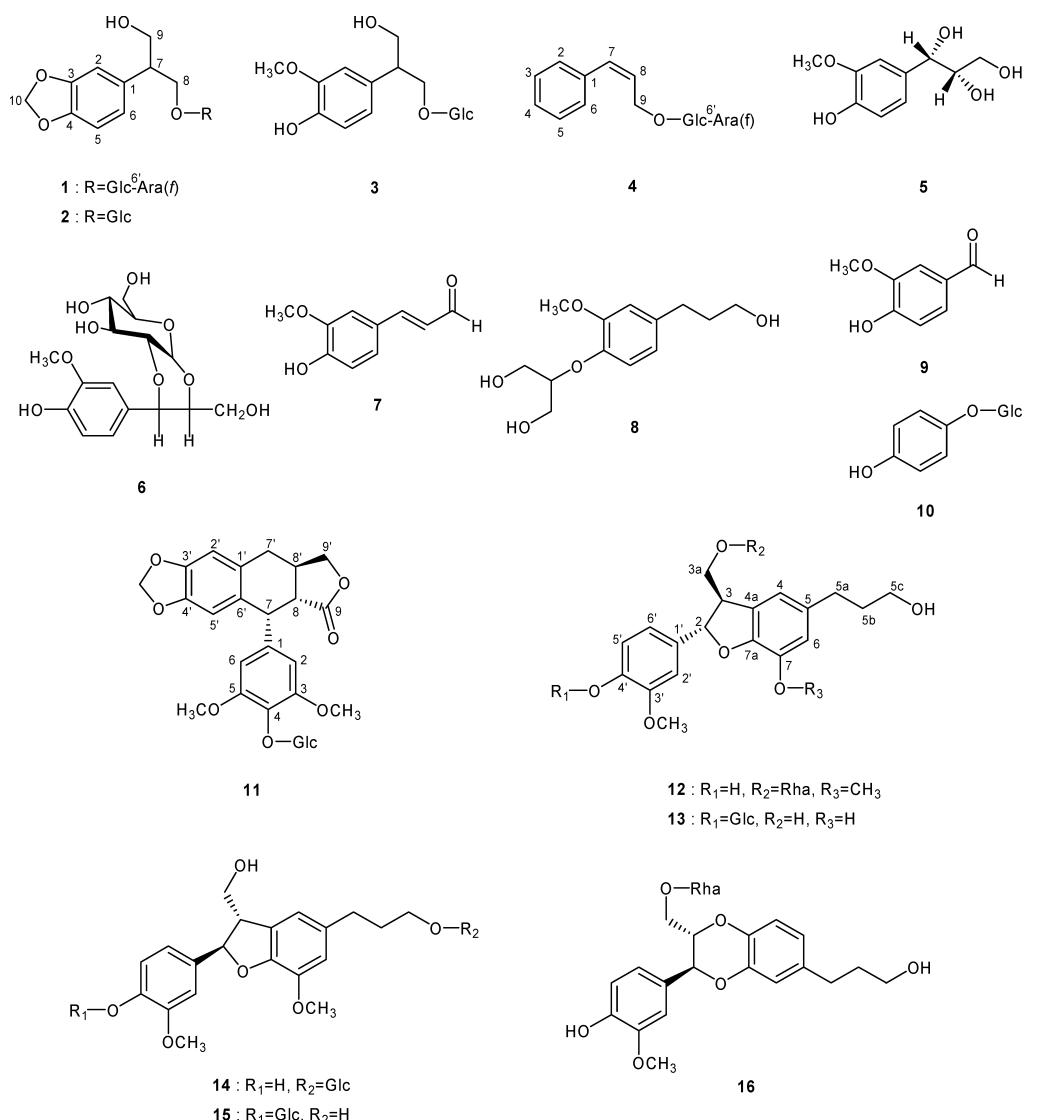

Chart 1

Table 1. ${ }^{1} \mathrm{H}-(600 \mathrm{MHz})$ and ${ }^{13} \mathrm{C}-\mathrm{NMR}(150 \mathrm{MHz})$ Spectral Data of $\mathbf{1}$ and 4 in $\mathrm{MeOH}-d_{4}$

\begin{tabular}{|c|c|c|c|c|c|}
\hline \multirow{2}{*}{\multicolumn{2}{|c|}{ No. }} & \multicolumn{2}{|l|}{1} & \multicolumn{2}{|l|}{4} \\
\hline & & $\delta_{\mathrm{H}}$ & $\delta_{\mathrm{C}}$ & $\delta_{\mathrm{H}}$ & $\delta_{\mathrm{C}}$ \\
\hline & 1 & & 135.9 & & 137.9 \\
\hline & 2 & $6.83(\mathrm{~s})$ & 109.7 & $7.23-7.26(\mathrm{~m})^{a)}$ & 129.9 \\
\hline & 3 & & 149.0 & 7.35 (br dd, 7.6, 7.6) & 129.4 \\
\hline & 4 & & 147.7 & $7.23-7.26(\mathrm{~m})^{a)}$ & 128.3 \\
\hline & 5 & $6.73(\mathrm{~d}, 8.1)$ & 109.0 & 7.35 (br dd, 7.6, 7.6) & 129.4 \\
\hline & 6 & $6.75($ br d, 8.1$)$ & 122.6 & $7.23-7.26(\mathrm{~m})^{a)}$ & 129.9 \\
\hline & 7 & $3.02(\mathrm{~m})$ & 49.2 & $6.61(\mathrm{brd}, 11.6)$ & 132.8 \\
\hline \multirow{2}{*}{\multicolumn{2}{|c|}{8}} & $4.07(\mathrm{dd}, 10.6,7.6)$ & 72.2 & $5.90(\mathrm{ddd}, 11.6,6.9,6.0)$ & 129.4 \\
\hline & & $3.77(\mathrm{dd}, 10.6,4.0)$ & & & \\
\hline \multirow{2}{*}{\multicolumn{2}{|c|}{9}} & $3.84(\mathrm{dd}, 11.6,5.5)$ & 64.8 & $4.63(\mathrm{ddd}, 12.8,6.0,1.8)$ & 67.4 \\
\hline & & $3.73^{a)}$ & & $4.44(\mathrm{ddd}, 12.8,6.9,1.8)$ & \\
\hline & 10 & $5.88(\mathrm{~s})$ & 102.1 & & \\
\hline \multirow[t]{7}{*}{ Glc } & $1^{\prime}$ & $\begin{array}{l}4.28(\mathrm{~d}, 7.8) \\
4.29(\mathrm{~d}, 7.8)^{b)}\end{array}$ & $\begin{array}{l}104.6 \\
104.9^{b)}\end{array}$ & $4.32(\mathrm{~d}, 7.8)$ & 103.9 \\
\hline & $2^{\prime}$ & $3.17(\mathrm{dd}, 9.0,7.8)$ & 75.1 & $3.19(\mathrm{dd}, 9.0,7.8)$ & 75.1 \\
\hline & $3^{\prime}$ & $3.32(\mathrm{dd}, 9.0,9.0)$ & 78.0 & $3.34(\mathrm{dd}, 9.0,9.0)$ & 78.0 \\
\hline & $4^{\prime}$ & $3.26(\mathrm{dd}, 9.0,9.0)$ & 72.0 & $3.29(\mathrm{dd}, 9.0,9.0)$ & 71.9 \\
\hline & $5^{\prime}$ & $3.44(\mathrm{ddd}, 9.0,5.5,2.5)$ & 76.8 & $3.40(\mathrm{ddd}, 9.0,5.7,2.3)$ & 76.7 \\
\hline & $6^{\prime}$ & $4.02(\mathrm{dd}, 11.6,2.5)$ & 68.2 & $3.98(\mathrm{dd}, 11.2,2.3)$ & 68.0 \\
\hline & & $3.58(\mathrm{dd}, 11.6,5.5)$ & & $3.60(\mathrm{dd}, 11.2,5.7)$ & \\
\hline \multirow[t]{6}{*}{$\operatorname{Ara}(f)$} & $1^{\prime \prime}$ & $\begin{array}{l}4.96(\mathrm{br} \mathrm{s}) \\
4.95(\mathrm{br} \mathrm{s})^{b)}\end{array}$ & $\begin{array}{l}110.0 \\
109.8^{b)}\end{array}$ & $4.94(\mathrm{~d}, 1.5)$ & 109.9 \\
\hline & $2^{\prime \prime}$ & $3.99(\mathrm{dd}, 3.6,1.0)$ & 83.2 & $3.98(\mathrm{dd}, 3.3,1.5)$ & 83.1 \\
\hline & $3^{\prime \prime}$ & $3.82(\mathrm{dd}, 5.6,3.6)$ & 78.9 & $3.81(\mathrm{dd}, 5.5,3.3)$ & 78.9 \\
\hline & $4^{\prime \prime}$ & $3.96(\mathrm{ddd}, 5.6,5.6,4.0)$ & 85.9 & $3.95(\mathrm{ddd}, 5.5,5.5,3.3)$ & 85.9 \\
\hline & $5^{\prime \prime}$ & $3.77(\mathrm{dd}, 11.6,4.0)$ & 63.1 & $3.72(\mathrm{dd}, 11.8,3.3)$ & 63.1 \\
\hline & & $3.61(\mathrm{dd}, 11.6,5.6)$ & & $3.62(\mathrm{dd}, 11.8,5.5)$ & \\
\hline
\end{tabular}

a) Overlapping with other signals. b) Appeared as sets of signals.

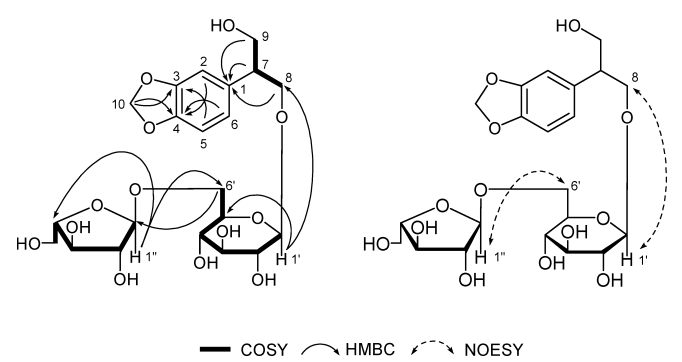

Fig. 1. Selected 2D NMR Sspectral Data of 1

at $m / z 383$ due to the loss of a hexosyl unit from the $[\mathrm{M}-\mathrm{H}]^{-}$ ion. The ${ }^{1} \mathrm{H}$ - and ${ }^{13} \mathrm{C}$-NMR spectral data exhibited the presence of a $\beta$-D-glucopyranosyl moiety as the sugar part (Table 2 ). The ${ }^{1} \mathrm{H}-\mathrm{NMR}$ and ${ }^{1} \mathrm{H}-{ }^{1} \mathrm{H}$ COSY spectra indicated the presence of a 1,2,3,5-tetrasubstituted benzene ring [ $\delta 6.33$ $(2 \mathrm{H}$, br s, $\mathrm{H}-2$ and $\mathrm{H}-6)]$, a 1,2,4,5-tetrasubstituted benzene ring $\left[\delta 6.62\left(1 \mathrm{H}, \mathrm{s}, \mathrm{H}-2^{\prime}\right)\right.$ and $\left.6.34\left(1 \mathrm{H}, \mathrm{s}, \mathrm{H}-5^{\prime}\right)\right]$, two methoxy groups $[\delta 3.63(6 \mathrm{H}, \mathrm{s})]$, a methylenedioxy group $[\delta$ $5.80(1 \mathrm{H}, \mathrm{d}, J=1.2 \mathrm{~Hz})$ and $5.79(1 \mathrm{H}, \mathrm{d}, J=1.2 \mathrm{~Hz})]$, and aliphatic $\left[-\mathrm{CH}_{2}-\mathrm{CH}\left(\mathrm{CH}_{2}\right)-\mathrm{CH}(\mathrm{CO})-(\mathrm{C}) \mathrm{CH}(\mathrm{C})-\right]$ proton signals as the aglycone moiety of $\mathbf{1 1}$ (Table 2). The ${ }^{1} \mathrm{H}-{ }^{1} \mathrm{H}$ COSY and HMBC correlations (Fig. 2) indicated that the plane structure of the aglycone of $\mathbf{1 1}$ was the same as that of 4-demethyldeoxypodophyllotoxin. The HMBC and NOESY correlations (Fig. 2) indicated that the $\beta$-D-glucosyl moiety was linked to the 4-OH of the aglycone through a glycosidic bond. The absolute configurations of the three chiral centers of the aglycone were determined as follows. Klyne et al. reported that $7 \alpha$-aryl $(=7 R)$ derivatives in 7 -aryltetralin type 
Table 2. ${ }^{1} \mathrm{H}-(600 \mathrm{MHz})$ and ${ }^{13} \mathrm{C}-\mathrm{NMR}(150 \mathrm{MHz})$ Spectral Data of $\mathbf{1 1}$ in $\mathrm{MeOH}-d_{4}$

\begin{tabular}{|c|c|c|}
\hline \multirow{2}{*}{ No. } & \multicolumn{2}{|l|}{11} \\
\hline & $\delta_{\mathrm{H}}$ & $\delta_{\mathrm{C}}$ \\
\hline 1 & \multirow{5}{*}{$6.33(\mathrm{~s})$} & 139.3 \\
\hline 2 & & 110.2 \\
\hline 3 & & 153.5 \\
\hline 4 & & 135.3 \\
\hline 5 & & 153.5 \\
\hline 6 & $6.33(\mathrm{~s})$ & 110.2 \\
\hline 7 & $4.48(\mathrm{~d}, 5.4)$ & 45.0 \\
\hline 8 & \multirow[t]{3}{*}{$2.81(\mathrm{dd}, 13.8,5.4)$} & 48.3 \\
\hline 9 & & 177.7 \\
\hline $1^{\prime}$ & & 130.4 \\
\hline $2^{\prime}$ & \multirow[t]{3}{*}{$6.62(\mathrm{~s})$} & 109.6 \\
\hline $3^{\prime}$ & & 148.5 \\
\hline $4^{\prime}$ & & 148.1 \\
\hline $5^{\prime}$ & \multirow[t]{2}{*}{$6.34(\mathrm{~s})$} & 111.1 \\
\hline $6^{\prime}$ & & 131.9 \\
\hline \multirow[t]{2}{*}{$7^{\prime}$} & \multirow{2}{*}{\multicolumn{2}{|c|}{$\begin{array}{l}2.70(\mathrm{dd}, 16.2,11.4) \\
2.98(\mathrm{dd}, 16.2,5.4)\end{array}$}} \\
\hline & & \\
\hline $8^{\prime}$ & $2.61(\mathrm{~m})$ & 34.4 \\
\hline \multirow[t]{2}{*}{$9^{\prime}$} & $3.88(\mathrm{dd}, 10.8,8.4)$ & 73.6 \\
\hline & \multicolumn{2}{|l|}{$4.35(\mathrm{dd}, 8.4,7.2)$} \\
\hline $3,5-\mathrm{OCH}_{3}$ & $3.63(6 \mathrm{H}, \mathrm{s})$ & 57.0 \\
\hline \multirow[t]{2}{*}{$\mathrm{O}-\mathrm{CH}_{2}-\mathrm{O}$} & $5.79(\mathrm{~d}, 1.2)$ & 102.5 \\
\hline & \multicolumn{2}{|l|}{$5.80(\mathrm{~d}, 1.2)$} \\
\hline Glc $1^{\prime \prime}$ & $4.74(\mathrm{~d}, 7.8)$ & 105.5 \\
\hline $2^{\prime \prime}$ & $3.35(\mathrm{dd}, 9.0,9.0)$ & 75.7 \\
\hline $3^{\prime \prime}$ & $3.31(\mathrm{dd}, 9.0,9.0)$ & 77.8 \\
\hline $4^{\prime \prime}$ & $3.32(\mathrm{dd}, 9.3,9.0)$ & 71.3 \\
\hline $5^{\prime \prime}$ & $3.10(\mathrm{ddd}, 9.0,4.8,2.4)$ & 78.2 \\
\hline \multirow[t]{2}{*}{$6^{\prime \prime}$} & $3.56(\mathrm{dd}, 12.0,4.8)$ & 62.6 \\
\hline & \multicolumn{2}{|l|}{$3.68(\mathrm{dd}, 12.0,2.4)$} \\
\hline
\end{tabular}

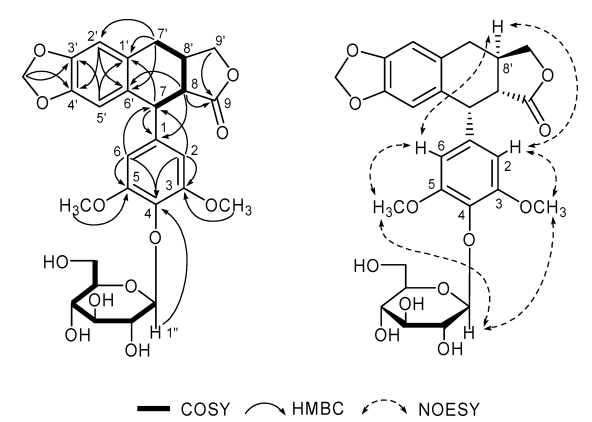

Fig. 2. Selected 2D NMR Spectral Data of $\mathbf{1 1}$

lignans afforded the positive Cotton effect around 280-290 $\mathrm{nm}$, while $7 \beta$-aryl $(=7 S)$ derivatives showed the negative Cotton curve in the CD spectrum. ${ }^{17,18)}$ Consequently, 11 showed a positive Cotton effect at $288 \mathrm{~nm}$ and hence, the absolute configuration at $\mathrm{C}-7$ was determined to be $R$. The large coupling constant between H-8 and H- $8^{\prime}(J=13.8$ $\mathrm{Hz})$ as well as the NOESY correlations between H-2, H-6 and $\mathrm{H}-\mathrm{8}^{\prime}$ (Fig. 2) indicated the $\mathrm{H}-8 / \mathrm{H}-8^{\prime}$ trans-configuration. Therefore, the absolute configurations of $\mathrm{C}-8$ and $\mathrm{C}-8^{\prime}$ were assigned as both $R$. Based on the evidence, the structure of 11 was determined to be $\left(7 R, 8 R, 8^{\prime} R\right)$-4-demethyldeoxypodophyllotoxin $4-O-\beta$-D-glucopyranoside. Up to now, 4demethyldeoxypodophyllotoxin 4-O-glucopyranoside, having the same planar structure as the aglycone part in 11, have already been isolated from Podophyllum emodi ${ }^{19)} P$.
Table 3. ${ }^{1} \mathrm{H}-(600 \mathrm{MHz})$ and ${ }^{13} \mathrm{C}-\mathrm{NMR}(150 \mathrm{MHz})$ Spectral Data of $\mathbf{1 2}$ and 14 in $\mathrm{MeOH}-d_{4}$

\begin{tabular}{|c|c|c|c|c|}
\hline \multirow{2}{*}{ No. } & \multicolumn{2}{|l|}{12} & \multicolumn{2}{|l|}{14} \\
\hline & $\delta_{\mathrm{H}}$ & $\delta_{\mathrm{C}}$ & $\delta_{\mathrm{H}}$ & $\delta_{\mathrm{C}}$ \\
\hline 2 & $5.46(\mathrm{~d}, 6.6)$ & 89.5 & $5.49(\mathrm{~d}, 6.3)$ & 89.1 \\
\hline 3 & $3.63(\mathrm{~m})$ & 52.8 & $3.47(\mathrm{br} \mathrm{q}, 6.3)$ & 55.5 \\
\hline \multirow[t]{2}{*}{$3 a$} & $3.89(\mathrm{dd}, 9.7,7.6)$ & $70.2^{a)}$ & $3.83(\mathrm{dd}, 11.1,5.5)$ & 65.1 \\
\hline & $3.72(\mathrm{dd}, 9.7,5.3)$ & & $3.76(\mathrm{dd}, 11.1,7.3)$ & \\
\hline 4 & $6.70(\mathrm{brs})$ & 117.7 & $6.75(\mathrm{brs})$ & $118.2^{b)}$ \\
\hline $4 a$ & & 129.5 & & 129.9 \\
\hline 5 & & 137.0 & & 136.9 \\
\hline $5 \mathrm{a}$ & $2.63(\mathrm{t}, 7.3)$ & 32.9 & $2.68(\mathrm{t}, 7.8)$ & 33.0 \\
\hline $5 b$ & $1.82(\mathrm{tt}, 7.3,6.6)$ & 35.7 & 1.90 (br quint, 6.6) & 33.0 \\
\hline $5 \mathrm{c}$ & $3.56(\mathrm{t}, 6.6)$ & 62.2 & $\begin{array}{l}3.92(\mathrm{dt}, 9.6,6.3) \\
3.53(\mathrm{dt}, 9.6,6.3)\end{array}$ & 70.0 \\
\hline 6 & $6.73(\mathrm{brs})$ & 114.3 & 6.75 (brs) & $114.3^{b)}$ \\
\hline 7 & & 145.2 & & 145.3 \\
\hline $7 \mathrm{a}$ & & $147.5^{c)}$ & & 147.6 \\
\hline $1^{\prime}$ & & 134.5 & & 134.9 \\
\hline $2^{\prime}$ & $6.94(\mathrm{~d}, 1.8)$ & 110.5 & $6.95(\mathrm{~d}, 1.8)$ & 110.6 \\
\hline $3^{\prime}$ & & 149.1 & & 149.2 \\
\hline $4^{\prime}$ & & $147.6^{c)}$ & & 147.6 \\
\hline $5^{\prime}$ & $6.78(\mathrm{~d}, 8.1)$ & 116.2 & $6.76(\mathrm{~d}, 8.1)$ & 116.2 \\
\hline $6^{\prime}$ & $6.82(\mathrm{dd}, 8.1,1.8)$ & 119.8 & $6.82(\mathrm{dd}, 8.1,1.8)$ & 119.8 \\
\hline $7-\mathrm{OCH}_{3}$ & $3.85(\mathrm{~s})$ & 56.8 & $3.85(\mathrm{~s})$ & 56.9 \\
\hline $3^{\prime}-\mathrm{OCH}_{3}$ & $3.82(\mathrm{~s})$ & 56.5 & $3.81(\mathrm{~s})$ & 56.4 \\
\hline Rha $1^{\prime \prime}$ & $4.73(\mathrm{~d}, 1.6)$ & 101.7 & & \\
\hline $2^{\prime \prime}$ & $3.81(\mathrm{dd}, 3.3,1.6)$ & 72.2 & & \\
\hline $3^{\prime \prime}$ & $3.59(\mathrm{dd}, 9.6,3.3)$ & 72.5 & & \\
\hline $4^{\prime \prime}$ & $3.37(\mathrm{dd}, 9.6,9.3)$ & 73.8 & & \\
\hline $5^{\prime \prime}$ & $3.52(\mathrm{dd}, 9.3,6.3)$ & $70.3^{a)}$ & & \\
\hline $6^{\prime \prime}$ & $1.25(\mathrm{~d}, 6.3)$ & 18.0 & & \\
\hline Glc $1^{\prime \prime \prime}$ & & & $4.25(\mathrm{~d}, 7.8)$ & 104.6 \\
\hline $2^{\prime \prime \prime}$ & & & $3.20(\mathrm{dd}, 7.8,9.0)$ & 75.3 \\
\hline $3^{\prime \prime \prime}$ & & & $3.35(\mathrm{dd}, 9.0,9.0)$ & 78.2 \\
\hline $4^{\prime \prime \prime}$ & & & $3.29(\mathrm{dd}, 9.0,9.0)$ & 71.8 \\
\hline $5^{\prime \prime \prime}$ & & & 3.25 (ddd, $9.0,5.5,2.3)$ & 78.0 \\
\hline $6^{\prime \prime \prime}$ & & & $3.85(\mathrm{dd}, 11.8,2.3)$ & 62.9 \\
\hline & & & $3.66(\mathrm{dd}, 11.8,5.5)$ & \\
\hline
\end{tabular}

a) -c) Assignments are interchangeable.

peltatum, ${ }^{19)}$ and $P$. versipelle. ${ }^{20)}$ However, in these papers, unambiguous structural determination procedures were not discussed and hence the absolute structure of $\mathbf{1 1}$ is represented here for the first time.

Compound 12, a white amorphous powder, gave a molecular formula of $\mathrm{C}_{26} \mathrm{H}_{34} \mathrm{O}_{10}$ based on the $[\mathrm{M}-\mathrm{H}]^{-}$ion peak at $m / z 505.2073$ in the negative ion HR-FAB-MS. The ${ }^{1} \mathrm{H}-$ and ${ }^{13} \mathrm{C}$-NMR spectra suggested that $\mathbf{1 2}$ was a dihydrobenzofuran-type neolignan glycoside carrying an $\alpha$-L-rhamnopyranosyl moiety as a sugar part (Table 3). The structure of the aglycone in 12 was elucidated from ${ }^{1} \mathrm{H}-{ }^{1} \mathrm{H}$ COSY and HMBC experiments (Fig. 3). The relative configurations of $\mathrm{H}-2$ and $\mathrm{H}-3$ were determined to be trans based on the NOESY correlations $\left(\mathrm{H}-2 / \mathrm{H}_{2}-3 \mathrm{a}\right.$ and $\mathrm{H}-3 / \mathrm{H}-2^{\prime}, \mathrm{H}-6^{\prime}$ ) (Fig. 3 ). The positive Cotton effect at $241 \mathrm{~nm}$ in the $\mathrm{CD}$ spectrum assigned the absolute stereochemistries of C-2 and C-3 to be $S$ and $R$, respectively. ${ }^{15)}$ In conclusion, the structure of $\mathbf{1 2}$ is determined to be $(2 S, 3 R)$-2,3-dihydro-3-hydroxymethyl-7methoxy-2-(4'-hydroxy-3'-methoxyphenyl)-5-benzofuranpropanol $3 \mathrm{a}-O-\alpha$-L-rhamnopyranoside. Dihydrobenzofurantype neolignan rhamnosides, having the same plane structure as the aglycone part in $\mathbf{1 2}$, have already been isolated from Pinus massoniana ${ }^{21)}$ Baseonema acuminatum, ${ }^{22)}$ and Junipe- 


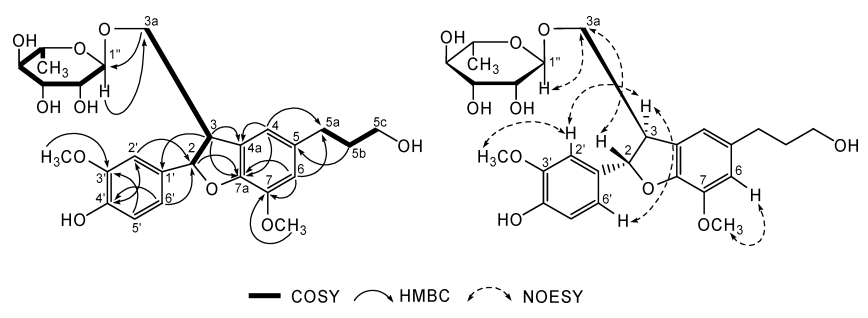

Fig. 3. Selected 2D NMR Spectral Data of $\mathbf{1 2}$

rus polycarpus. ${ }^{23)}$ However, in these papers, the absolute configurations on the dihydrobenzofuran ring were not discussed and hence the absolute structure of $\mathbf{1 2}$ based on CD analyses is represented here for the first time.

Compound 14, a white amorphous powder, had the molecular formula $\mathrm{C}_{26} \mathrm{H}_{34} \mathrm{O}_{11}$, which was determined based on the $[\mathrm{M}-\mathrm{H}]^{-}$ion at $\mathrm{m} / \mathrm{z} 521.2038$ in negative ion HR-FAB-MS. The ${ }^{1} \mathrm{H}$ - and ${ }^{13} \mathrm{C}$-NMR spectral data exhibited the presence of a $\beta$-D-glucopyranosyl moiety as the sugar part. In addition the ${ }^{1} \mathrm{H}$ - and ${ }^{13} \mathrm{C}$-NMR spectral data of the aglycone of 14 was almost same with those of $\mathbf{1 2}$ (Table 3). The CD Cotton curve of $\mathbf{1 4}$ was opposite to that of 12, suggesting that the aglycone of $\mathbf{1 4}$ was the enantiomer of the aglycone of $\mathbf{1 2}$. On the basis of the above evidence as well as the precise spectroscopic analyses, the structure of $\mathbf{1 4}$ was determined to be $(2 R, 3 S)$-2,3-dihydro-3-hydroxymethyl-7-methoxy-2-(4' -hydroxy-3'-methoxyphenyl)-5-benzo-furanpropanol $5 \mathrm{c}-O-\beta$-Dglucopyranoside. Calis et al. reported the isolation of a dihydrobenzofuran-type neolignan glucoside having the same structure as $\mathbf{1 4}$ from Phlomis viscose. ${ }^{24)}$ However, no chemical and spectral data of this compound were provided in the report. Thus the ${ }^{1} \mathrm{H}$ - and ${ }^{13} \mathrm{C}-\mathrm{NMR}$ assignments in Table 3 and other physical properties in the experimental are reported here for the first time.

\section{Experimental}

${ }^{1} \mathrm{H}$ - and ${ }^{13} \mathrm{C}$-NMR spectra were measured on a JEOL JNM-ECA $600\left({ }^{1} \mathrm{H}\right.$ at $600 \mathrm{MHz}$ and ${ }^{13} \mathrm{C}$ at $\left.150 \mathrm{MHz}\right)$ or JEOL JNM-GX $400\left({ }^{1} \mathrm{H}\right.$ at $400 \mathrm{MHz}$ and ${ }^{13} \mathrm{C}$ at $100 \mathrm{MHz}$ ) spectrometer. Chemical shifts are given in $\delta$ values (ppm) relative to tetramethylsilane (TMS) as an internal standard. FAB- and HR-FAB-MS spectra in negative mode (matrix, triethanolamine) were obtained with a JEOL JMS-700T spectrometer. Optical rotations were recorded on a JASCO P-1020 polarimeter and CD spectra on a JASCO J-805 spectropolarimeter, respectively. IR and UV spectra were measured on JASCO FT/IR-410 and Shimadzu UV-1600 UV/VIS spectrophotometers, respectively. For column chromatography, silica gel 60 (230-400 mesh, Merck), Chromatorex ODS DM1020T (100-200 mesh, Fuji Silysia), and Sephadex LH-20 (Amersham Biosciences) were used. Kiesel gel $60 \mathrm{~F}_{254}$ (Merck) and RP-18 $\mathrm{F}_{254}$ (Merck) were used for analytical TLC. Preparative HPLC was performed on a JAI LC-918 instrument with an RI-50 differential refractometer and a JAIGEL-ODS or a JAIGEL-GS 310 column, and also on a JASCO PU-2086 instrument with an RI-2031 differential refractometer and a TSK gel ODS- $80 \mathrm{~T}_{\mathrm{S}}$ column.

Plant Material The leaves and stems of $J$ communis var. depressa were collected in July 1997, in Oregon, U.S.A. A voucher specimen (Murata et al., No. 053) was deposited in the Herbarium, Botanical Gardens, The University of Tokyo (TI), Japan.

Extraction and Isolation The dried and cut materials $(2.4 \mathrm{~kg})$ were extracted three times with $\mathrm{MeOH}(181 \times$ weekly) at room temperature. The $\mathrm{MeOH}$ solution was evaporated in vacuo to afford a dark greenish extract $(488 \mathrm{~g})$, an aliquot $(202 \mathrm{~g})$ of which was partitioned between $n$-hexane and $\mathrm{MeOH}$. The MeOH-soluble part $(130 \mathrm{~g})$ was further partitioned between $n$ $\mathrm{BuOH}$ and water. The resulting $n$ - $\mathrm{BuOH}$ extract $(76 \mathrm{~g})$ was chromatographed on silica gel and eluted with $\mathrm{CHCl}_{3}-\mathrm{MeOH}-\mathrm{H}_{2} \mathrm{O}(7: 3: 1$, a lower phase) to give 10 fractions (for each fraction, the abbreviations from $\mathrm{A}$ to $\mathrm{J}$ are used). Fraction D (1.32 g) was divided into 5 subfractions (from D-1 to D-5) with a
Sephadex LH-20 column eluted with MeOH. Fraction D-2 was purified by repeated HPLC separation using JAIGEL-GS column (eluted with $50 \%$ $\mathrm{MeOH})$ to give $11(12.0 \mathrm{mg})$ and another crude fraction. The crude fraction was further purified with HPLC (JAIGEL-ODS; eluted with $60 \% \mathrm{MeOH}$ ) to give $8(0.9 \mathrm{mg})$. Fraction $\mathrm{E}(4.21 \mathrm{~g})$ was divided into two subfractions (E-1 and E-2) with a Sephadex LH-20 column eluted with acetone. Fraction E-2 was separated with Sephadex LH 20 column chromatography (eluted with $70 \%$ Acetone) into four subfractions. Subfraction 2 was applied to ODS column chromatography eluted with $60 \% \mathrm{MeOH}$ to afford six fractions. The sixth fraction was further purified with HPLC (JAIGEL-ODS; eluted with $50 \% \mathrm{MeOH})$ to give $\mathbf{1 2}(8.3 \mathrm{mg})$. Subfraction 4 was further purified with HPLC (JAIGEL-GS; eluted with $60 \% \mathrm{MeOH})$ to give $\mathbf{1 6}(6.4 \mathrm{mg})$. Fraction $\mathrm{F}(6.2 \mathrm{~g})$ was subsequently fractionated with silica gel column chromatography $\left[\mathrm{CHCl}_{3}-\mathrm{MeOH}-\mathrm{H}_{2} \mathrm{O}(9: 3: 1\right.$, a lower phase)] into two subfractions (F1 and F-2). Fraction F-2 was separated with Sephadex LH-20 column chromatography (eluted with $\mathrm{MeOH}$ ) followed by ODS column chromatography (eluted with $50 \% \mathrm{MeOH}$ ) to afford three subfractions. Subfraction 1 was further purified with HPLC (JAIGEL-GS; eluted with $\mathrm{MeOH}$ ) to give 7 $(3.8 \mathrm{mg})$ and $9(3.8 \mathrm{mg})$. Subfraction 3 was further purified with HPLC (JAIGEL-GS; eluted with $50 \% \mathrm{MeOH})$ to give $\mathbf{5}(3.3 \mathrm{mg})$. The fraction $\mathrm{G}$ $(8.8 \mathrm{~g})$ was applied onto a Sephadex LH-20 column (eluted with $\mathrm{MeOH}$ ) followed by ODS column chromatography (eluted successively with $50 \%$ $\mathrm{MeOH}, 70 \% \mathrm{MeOH}$ and $\mathrm{MeOH}$ ) to divide five subfractions (from G-1 to G5). Fraction G-3 was separated with ODS column chromatography (eluted with $50 \% \mathrm{MeOH}$ ) into four subfractions. Subfraction 3 was applied to ODS column chromatography (eluted with $40 \% \mathrm{MeOH}$ ) and HPLC (JAIGEL-GS; eluted with $50 \% \mathrm{MeOH}$ ) to afford four subfractions. The second fraction was further purified with HPLC (TSK gel ODS- $80 \mathrm{~T}_{\mathrm{S}}$; eluted with $50 \%$ $\mathrm{MeOH})$ to give $2(23.3 \mathrm{mg})$. The fourth fraction was further purified with HPLC (TSK gel ODS- $80 \mathrm{~T}_{\mathrm{S}}$; eluted with $50 \% \mathrm{MeOH}$ ), followed by HPLC (JAIGEL-GS; eluted with $50 \% \mathrm{MeOH})$ to afford $\mathbf{1 4}(1.8 \mathrm{mg})$. Subfraction 4 was further purified with HPLC (JAIGEL-ODS; eluted with $50 \% \mathrm{MeOH}$ ) to give $15(6.4 \mathrm{mg})$. Fraction G-5 was subjected to ODS column chromatography (eluted with $50 \% \mathrm{MeOH}$ ) to separate three subfractions. Subfraction 1 was further purified by HPLC (JAIGEL-ODS; eluted with $50 \% \mathrm{MeOH}$ ) to give $4(2.4 \mathrm{mg})$. Fraction $\mathrm{H}(10.8 \mathrm{~g})$ was divided into 13 fractions (from $\mathrm{H}-1$ to $\mathrm{H}-13$ ) with ODS column chromatography eluted with $50 \% \mathrm{MeOH}$. Fraction H-8 was purified by ODS column chromatography (eluted with $50 \%$ $\mathrm{MeOH})$ to be divided into six subfractions. Subfraction 4 was further purified by HPLC (JAIGEL-GS; eluted with $50 \% \mathrm{MeOH})$ to give $\mathbf{1}(14.5 \mathrm{mg})$. Fraction $\mathrm{H}-9$ was subsequently fractionated with silica gel column chromatography $\left[\mathrm{CHCl}_{3}-\mathrm{MeOH}-\mathrm{H}_{2} \mathrm{O}(7: 3: 1\right.$, a lower phase)] into four subfractions. Subfraction 1 was divided into two fractions with ODS column chromatography eluted with $15 \% \mathrm{MeOH}$. The latter fraction was further purified by HPLC (TSK gel ODS- $80 \mathrm{~T}_{\mathrm{S}}$; eluted with $15 \% \mathrm{MeOH}$ ) to give 6 $(22.3 \mathrm{mg})$. Subfraction 2 was subjected to ODS column chromatography eluted with $30 \% \mathrm{MeOH}$, followed by HPLC (TSK gel ODS- $80 \mathrm{~T}_{\mathrm{S}}$; eluted with $15 \% \mathrm{MeOH})$ to afford $\mathbf{3}(17.8 \mathrm{mg})$ and $\mathbf{1 0}(4.0 \mathrm{mg})$. Subfraction 3 was divided into three fractions with HPLC (JAIGEL-GS; eluted with $50 \%$ $\mathrm{MeOH}$ ) and the resulting second fraction was purified by HPLC (TSK gel ODS- $80 \mathrm{~T}_{\mathrm{s}}$; eluted with $\left.40 \% \mathrm{MeOH}\right)$ to give $\mathbf{1 3}(7.2 \mathrm{mg})$.

Junipediol B 8-O-(6'-O- $\alpha$-L-arabinofuranosyl)- $\beta$-D-glucopyranoside (1): A white amorphous powder, $[\alpha]_{\mathrm{D}}-18.9^{\circ}(c=0.40, \mathrm{MeOH})$. HR-FAB-MS (negative mode) $m / z$ : $489.1604[\mathrm{M}-\mathrm{H}]^{-}$(Calcd for $\left.\mathrm{C}_{21} \mathrm{H}_{29} \mathrm{O}_{13}, 489.1608\right)$. IR (film) $\mathrm{cm}^{-1}: 3350,2924,1069,1038$. UV $\lambda_{\max }(\mathrm{MeOH}) \mathrm{nm}(\log \varepsilon): 204$ (4.30), 228 (sh, 3.73), 284 (3.50). ${ }^{1} \mathrm{H}$ - and ${ }^{13} \mathrm{C}-\mathrm{NMR}$ data are given in Table 1. cis-Cinnamyl Alcohol 9-O-(6'-O- $\alpha$-L-arabinofuranosyl)- $\beta$-D-glucopyranoside (4): A white amorphous powder, $[\alpha]_{\mathrm{D}}-70.1^{\circ}(c=0.89, \mathrm{MeOH})$. FAB- and HR-FAB-MS (negative mode) $m / z$ : $427.1615[\mathrm{M}-\mathrm{H}]^{-}$(Calcd for $\left.\mathrm{C}_{20} \mathrm{H}_{27} \mathrm{O}_{10}, 427.1604\right), 295[\mathrm{M}-\mathrm{H}-\mathrm{Ara}(f)]^{-}$. IR (film) $\mathrm{cm}^{-1}: 3358,2926$, 1069, 1041. UV $\lambda_{\max }(\mathrm{MeOH}) \mathrm{nm}(\log \varepsilon): 207$ (4.21), 244 (3.98). ${ }^{1} \mathrm{H}-$ and ${ }^{13} \mathrm{C}$-NMR data are given in Table 1.

$\left(7 R, 8 R, 8^{\prime} R\right)$-4-Demethyldeoxypodophyllotoxin 4 - $O$ - $\beta$-D-glucopyranoside (11): A white amorphous powder, $[\alpha]_{\mathrm{D}}-45.7^{\circ}(c=0.47, \mathrm{MeOH})$. FAB- and HR-FAB-MS (negative mode) $\mathrm{m} / \mathrm{z}$ : $545.1667[\mathrm{M}-\mathrm{H}]^{-}$(Calcd for $\left.\mathrm{C}_{27} \mathrm{H}_{29} \mathrm{O}_{12}, 545.1659\right), 383[\mathrm{M}-\mathrm{H}-162]^{-}$. IR (film) $\mathrm{cm}^{-1}: 3375,2923$, $1767,1592,1485,1227,1122,1037$. UV $\lambda_{\max }(\mathrm{MeOH}) \mathrm{nm}(\log \varepsilon): 214$ (4.36), 230 (sh, 4.13), 290 (3.62). CD $\left(c=9.90 \times 10^{-5} \mathrm{~mol} / \mathrm{l}, \mathrm{MeOH}\right) \Delta \varepsilon(\lambda$ $\mathrm{nm}):-1.42(277),+0.23(288) .{ }^{1} \mathrm{H}-$ and ${ }^{13} \mathrm{C}-\mathrm{NMR}$ data are given in Table 2.

$(2 S, 3 R)-2,3$-Dihydro-3-hydroxymethyl-7-methoxy-2-(4'-hydroxy-3'methoxyphenyl)-5-benzofuranpropanol 3a- $O$ - $\alpha$-L-rhamnopyranoside (12): A white amorphous powder, $[\alpha]_{\mathrm{D}}-4.50^{\circ}(c=0.31, \mathrm{MeOH})$. HR-FAB-MS (negative mode) $\mathrm{m} / \mathrm{z}$ : $505.2073[\mathrm{M}-\mathrm{H}]^{-}$(Calcd for $\mathrm{C}_{26} \mathrm{H}_{33} \mathrm{O}_{10}, 505.2074$ ). IR (film) $\mathrm{cm}^{-1}$ : 3363, 2932, 1604, 1517, 1456, 1274, 1213, 1139, 1048. UV 
$\lambda_{\max }(\mathrm{MeOH}) \mathrm{nm}(\log \varepsilon): 210$ (4.48), 225 (sh, 4.20), 282 (3.85). CD $\left(c=7.95 \times 10^{-5} \mathrm{~mol} / \mathrm{l}, \mathrm{MeOH}\right) \Delta \varepsilon(\lambda \mathrm{nm}):+5.25(210),+0.36(225),+1.88$ $(241),+1.05$ (291). ${ }^{1} \mathrm{H}$ - and ${ }^{13} \mathrm{C}-\mathrm{NMR}$ data are given in Table 3.

$(2 R, 3 S)-2,3$-Dihydro-3-hydroxymethyl-7-methoxy-2-(4'-hydroxy-3' methoxyphenyl)-5-benzofuranpropanol $5 \mathrm{c}-O$ - $\beta$-D-glucopyranoside (14): A white amorphous powder, $[\alpha]_{\mathrm{D}}-12.4^{\circ}(c=0.18, \mathrm{MeOH})$. HR-FAB-MS (negative mode) $m / z$ : $521.2038[\mathrm{M}-\mathrm{H}]^{-}\left(\right.$Calcd for $\mathrm{C}_{26} \mathrm{H}_{33} \mathrm{O}_{11}, 521.2023$ ). IR (film) $\mathrm{cm}^{-1}: 3365,2936,1605,1518,1455,1276,1212,1030$. UV $\lambda_{\max }$ $(\mathrm{MeOH}) \mathrm{nm} \quad(\log \varepsilon): 210 \quad(4.54), 226 \quad(\mathrm{sh}, 4.21), 282 \quad(3.80) . \quad \mathrm{CD}$ $\left(c=6.90 \times 10^{-5} \mathrm{~mol} / \mathrm{l}, \mathrm{MeOH}\right) \Delta \varepsilon(\lambda \mathrm{nm}) ;-3.69(211),+0.23(225),-1.19$ (243), -0.54 (294). ${ }^{1} \mathrm{H}$ - and ${ }^{13} \mathrm{C}$-NMR data are given in Table 3.

Acid Hydrolysis of Compounds 1, 4, 11, 12, and 14 Each glycoside (ca. $1 \mathrm{mg})$ in $1 \mathrm{M} \mathrm{HCl}(1.0 \mathrm{ml})$ was heated at $95^{\circ} \mathrm{C}$ for $3 \mathrm{~h}$. After cooling, the reaction mixture was neutralized with Amberlite IRA-93ZU (Organo Co., Ltd., Tokyo, Japan) and passed through an OASIS HLB cartridge column. The solution was concentrated to give a sugar fraction, which was analyzed by HPLC under the following conditions: column, COSMOSIL Sugar-D (4.6 mm i.d. $\times 250 \mathrm{~mm}$, Nacalai Tesque Inc., Kyoto, Japan); solvent, $\mathrm{CH}_{3} \mathrm{CN}-$ $\mathrm{H}_{2} \mathrm{O}(4: 1)$; flow rate, $1.0 \mathrm{ml} / \mathrm{min}$; detection, optical rotation, JASCO OR2090 Plus. Identification of D-glucose (from 1, 4, 11, and 14), ${ }_{\mathrm{L}}$-arabinose (from 1 and 4), and L-rhamnose (from 12) present in the sugar fraction was carried out by comparison of their retention times $\left(t_{\mathrm{R}}\right)$ and optical rotations with those of authentic samples. $t_{\mathrm{R}}(\mathrm{min}): 11.6$ (D-glucose, positive optical rotation), 8.6 (L-arabinose, positive optical rotation), 6.9 (L-rhamnose, negative optical rotation).

Acknowledgments This work was supported in part by a Grant-in-Aid for Scientific Research (No. 09041194) from the Ministry of Education, Culture, Sports, Science and Technology in Japan. Thanks are due to Dr. Robert P. Adams, Director of the Pacific Center for Molecular Biodiversity, Bishop Museum, U.S.A., for identification of the plant.

\section{References and Notes}

1) Present address: San-Ei Gen F.F.I., Inc.; Toyonaka, Osaka 561-8588, Japan.

2) Nakanishi T., Iida N., Inatomi Y., Murata H., Inada A., Murata J., Lang F. A., Iinuma M., Tanaka T., Phytochemistry, 65, 207-213 (2004).

3) Nakanishi T., Iida N., Inatomi Y., Murata H., Inada A., Murata J., Lang F. A., Iinuma M., Tanaka T., Heterocycles, 63, 2573-2580 (2004).

4) Inatomi Y., Iida N., Murata H., Inada A., Murata J., Lang F. A., Iinuma M., Tanaka T., Nakanishi T., Tetrahedron Lett., 46, 6533-6535 (2005).

5) Nakanishi T., Iida N., Inatomi Y., Murata H., Inada A., Murata J., Lang
F. A., Iinuma M., Tanaka T., Sakagami Y., Chem. Pharm. Bull., 53, $783-787$ (2005).

6) Iida N., Inatomi Y., Murata H., Inada A., Murata J., Lang F. A., Matsuura N., Nakanishi T., Chem. Biodiversity, 4, 32-42 (2007).

7) Comte G., Allaris D. P., Chulia A. J., Vercauteren J., Pinaud N., Phytochemistry, 44, 1169-1173 (1997).

8) Ishikawa T., Fujimaru E., Kitajima J., Chem. Pharm. Bull., 50, 14601466 (2002).

9) Ishimaru K., Nonaka G., Nishioka I., Phytochemistry, 26, 1147-1152 (1987).

10) Comte G., Vercauteren J., Chulia A. J., Allais D. P., Delage C., Phytochemistry, 45, 1679-1682 (1997).

11) Baba K., Matsuyama Y., Fukumoto M., Hamasaki F., Kozawa M., Shoyakugaku Zasshi, 37, 418-421 (1983).

12) Kouno I., Yanagida Y., Shimono S., Shintomi M., Yang C.-S., Chem. Pharm. Bull., 40, 2461-2464 (1992).

13) Vanillin and arbutin were identified by comparison of their physical and spectral data with those of commercially available samples (Tokyo Kasei Kogyo).

14) Machida K., Takano M., Kakuda R., Yaoita Y., Kikuchi M., Chem. Pharm. Bull., 50, 669-671 (2002).

15) Matsuda N., Sato H., Yaoita Y., Kikuchi M., Chem. Pharm. Bull., 44, 1122-1123 (1996).

16) Xu J.-F., Cao D.-H., Tan N.-H., Liu Z.-L., Zhang Y.-M., Yang Y.-B., J. Asian Nat. Prod. Res., 8, 181-185 (2006).

17) Klyne W., Stevenson R., Swan R. J., J. Chem. Soc. C, 1966, 893-896 (1966).

18) Swan R. J., Klyne W., Maclean H., Can. J. Chem., 45, 319-324 (1967).

19) Wartburg A. von, Kuhn M., Lichti H., Helv. Chim. Acta, 47, 131-132 (1964).

20) Broomhead A. J., Dewick P. M., Phytochemistry, 29, 3831-3837 (1990)

21) Lundgren L. N., Shen Z., Theander O., Acta Chem. Scand. B, 39, 241-248 (1985)

22) Leo M. de, Braca A., Tommasi N. de, Norscia I., Morelli I., Battinelli L., Mazzanti G., Planta Med., 70, 841-846 (2004).

23) Okasaka M., Takaishi Y., Kashiwada Y., Kodzhimatov O. K., Ashurmetov O., Lin A. J., Consentino L. M., Lee K.-H., Phytochemistry, 67, 2635-2640 (2006).

24) Calis I., Kirmizibekmez H., Beutler J. A., Donmez A. A., Yalcin F. N., Kilic E., Ozalp M., Ruedi P., Tasdemir D., Turk. J. Chem., 29, 71-81 (2005). 